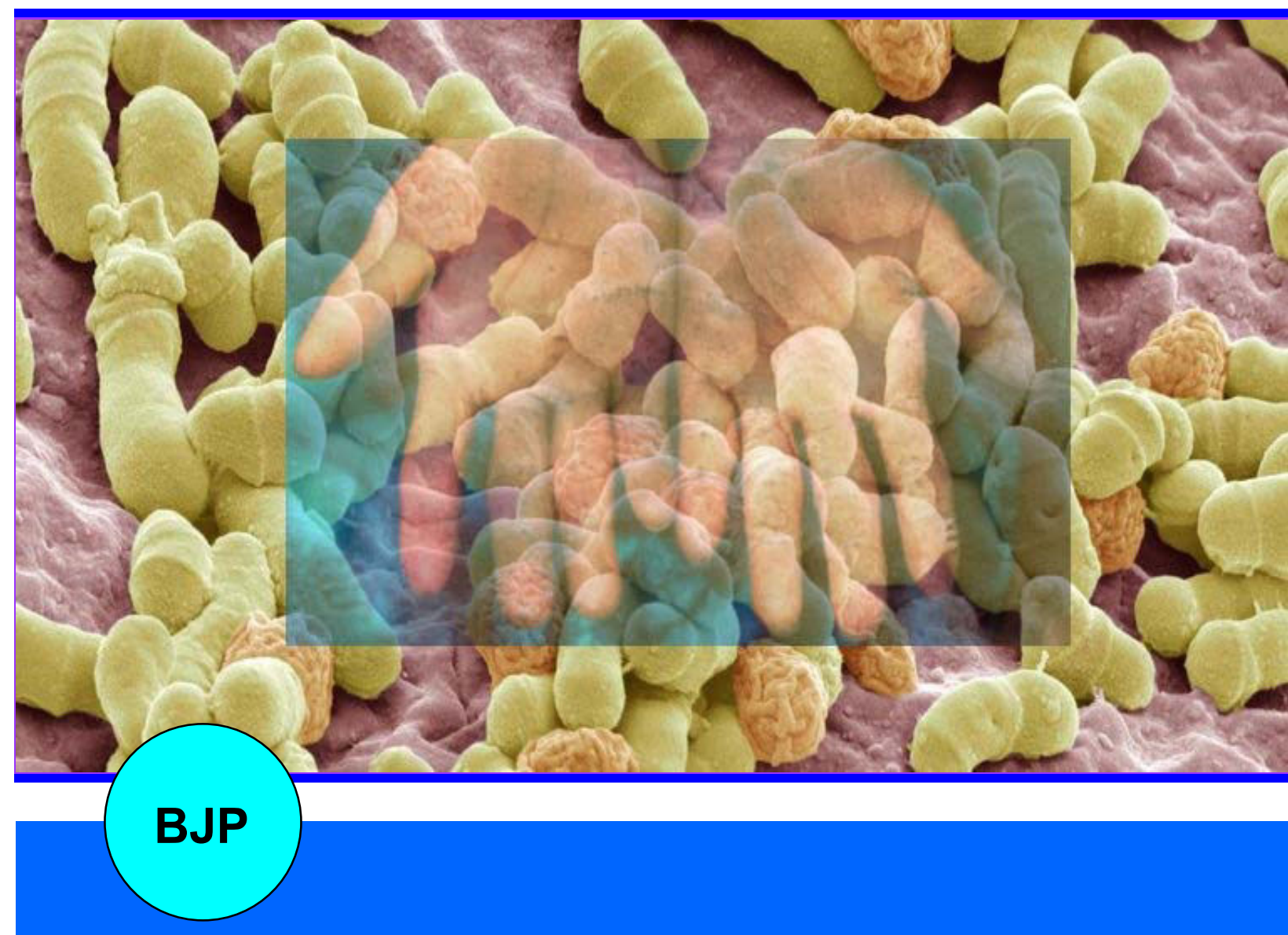

Bangladesh Journal of Pharmacology

Clinical Trial

Pattern of skin fungi in palmar arsenical keratosis 


\section{Pattern of skin fungi in palmar arsenical keratosis}

\section{Priyanka Moitra', Mir Misbahuddin' and Abu Naser Ibne Sattar²}

Department of ${ }^{1}$ Pharmacology, ${ }^{2}$ Microbiology and Immunology, Faculty of Basic Science and Paraclinical Science, Bangabandhu Sheikh Mujib Medical University, Shahbag, Dhaka, Bangladesh.

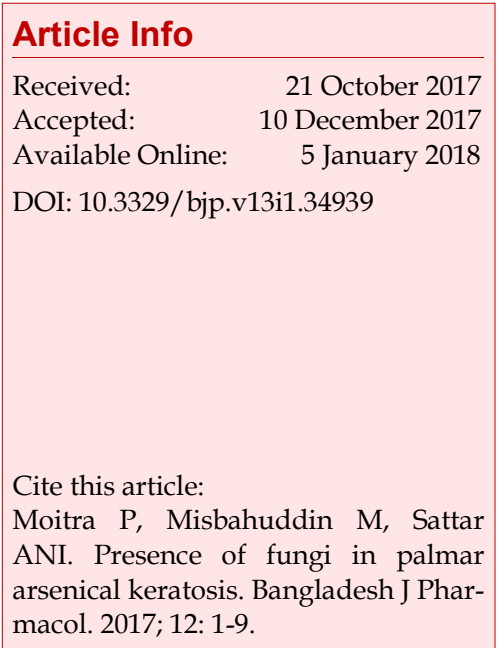

\begin{abstract}
The aim of this study was to examine the pattern of fungi in palmar arsenical keratosis. The skin swab was taken from the five different sites (palm, dorsum, axilla, front and back of the chest) of arsenicosis patients $(n=37)$, arsenic exposed volunteers $(n=20)$ and healthy volunteers $(n=20)$ of an arsenic endemic area. Fungi were cultured in the Sabouraud dextrose agar media. The skin of the healthy volunteers contained only four species of fungi: Aspergillus, Dermatophytes, Mucor and Fusarium. The incidence of each fungus was low (0-4 out of 20 cases). The chronic exposure to arsenic did not alter the pattern of fungi. However, the patient of arsenicosis showed increased incidence of Aspergillus and Dermatophytes species and decreased incidence of Mucor species. The supplementation of iron and folic acid to the patient for 12 weeks reduced the incidence of Aspergillus (only in axilla), Dermatophytes (only in palm) and increased the incidence of Mucor (all the sites except palm). In conclusion, skin fungi are altered in arsenicosis irrespective of intake of high concentration of arsenic.
\end{abstract}

\section{Introduction}

The chronic ingestion of high concentration of arsenic in the drinking water may lead to suffering from arsenicosis (Caussy, 2005; Misbahuddin, 2015). The common clinical manifestations appear in the skin. These are melanosis, leucomelanosis and keratosis (Saha, 1984; Guha Mazumder, 2003). Melanosis (black spots) usually unnoticed by the patient as it usually appears in the unexposed part of the body particularly in the chest (front and back) and thigh. It may be diffused or spotted. Leucomelanosis (yellow spots) usually appears as the rain-drop appearance. The appearance of leucomelanosis draws attention to the patient or his/her family member(s) to consult the physician for treatment. Keratosis (growth of keratin) usually appears in both palms and/or soles.

The skin of arsenical keratosis shows significantly low levels of vitamin $\mathrm{E}$ and linoleic acid in comparison to the skin of normal healthy individual of arsenic endemic area without any significant change in the level of zinc (Misbahuddin and Afrin, 2013).

Melanosis, leucomelanosis and keratosis do not affect the morbidity or mortality. The social and psychological problems develop due to the appearance of keratosis (moderate/severe form) in palms particularly in case of female (Hassan et al., 2005). It is, somewhat, difficult to give marriage of unmarried girl or may cause divorce in case of married woman (Brinkel et al., 2009). Thus, the treatment of keratosis is more important than that of the melanosis.

Melanosis usually disappears after stoppage of drinking arsenic contaminated water. However, leucomelanosis is considered as the recovery stage from the arsenicosis in the skin. The skin of leucomelanosis contains all-E lutein and 3'-epilutein (Misbahuddin et al., 2008). Keratosis remains even after the stoppage of drinking arsenic contaminated water. 
Keratosis can be treated by the oral administration of anti-oxidant vitamins [vitamin A (Hall, 1946), ascorbic acid, alpha-tocopherol, folic acid], selenium (Nasir et al., 2002), garlic and spirulina (Misbahuddin et al., 2006). The disadvantages of this therapy are the: a) prolonged duration of treatment and b) recurrence after stoppage of treatment. In addition, the topical application of salicylic acid (Islam et al., 2007), urea, propylene glycol (Dina and Misbahuddin, 2010) or neem (Ferdous and Misbahuddin, 2014) may be suggested. Among them, salicylic acid is used in high concentration (10$20 \%)$. It has keratolytic effect. There is burning sensation following the topical use of salicylic acid.

The human skin contains about $10^{11}$ bacteria (Sender et al., 2016). One study shows that the skin of the palm in arsenicosis patient has increased incidence of Enterobactor species (Khalil et al., 2016). It is not clear whether the alteration of bacterial pattern influences the growth of fungi in the skin. In addition, the role of fungi in the development of arsenical keratosis is unknown.

At least 36 million people in Bangladesh are consuming arsenic contaminated drinking water daily (Chakraborti et al., 2010). There are about 50,000 reported cases of arsenicosis with skin manifestations (Misbahuddin, 2015). In addition, about $26 \%$ of Bangladeshi women are suffering from anemia (National micronutrient survey in Bangladesh, 2011-2012). An animal study shows that anemia enhances the accumulation of arsenic in the tissue (Paul et al., 2002). On the other hand, supplementation of folic acid reduces the level of arsenic level in rat tissue (Rahman and Misbahuddin, 2010). The relationship between the long-term supplementation of iron and folic acid and the growth of fungi in the palm surface is not yet clear. Therefore, the present study has been designed a) whether arsenicosis alters the fungi and b) is there any change in the skin fungal pattern in patients with palmar arsenical keratosis after administering folic acid and iron.

\section{Materials and Methods}

\section{Place and duration of the study}

The study was conducted in three different places: a) Department of Pharmacology, Bangabandhu Sheikh Mujib Medical University, where the arsenic concentration in the drinking water and nail was estimated; $b$ ) Department of Microbiology and Immunology, Bangabandhu Sheikh Mujib Medical University, where the laboratory was used to culture and identify the fungi; c) Iruain Village, Kandirpar Union, Laksham Upazilla of Comilla District (Figure 1), where the enrolment of participants, collection of samples and distribution of iron and folic acid were done. Iruain Village is about $178 \mathrm{~km}$ away from the capital city, Dhaka.

The total population in Laksham Upazilla is 294,719. There are 376 registered patients of arsenicosis in the Laksham Upazilla Health Complex. Among them, 110 patients had moderate to severe palmar arsenical keratosis. Finally 37 patents voluntarily agreed to parti-

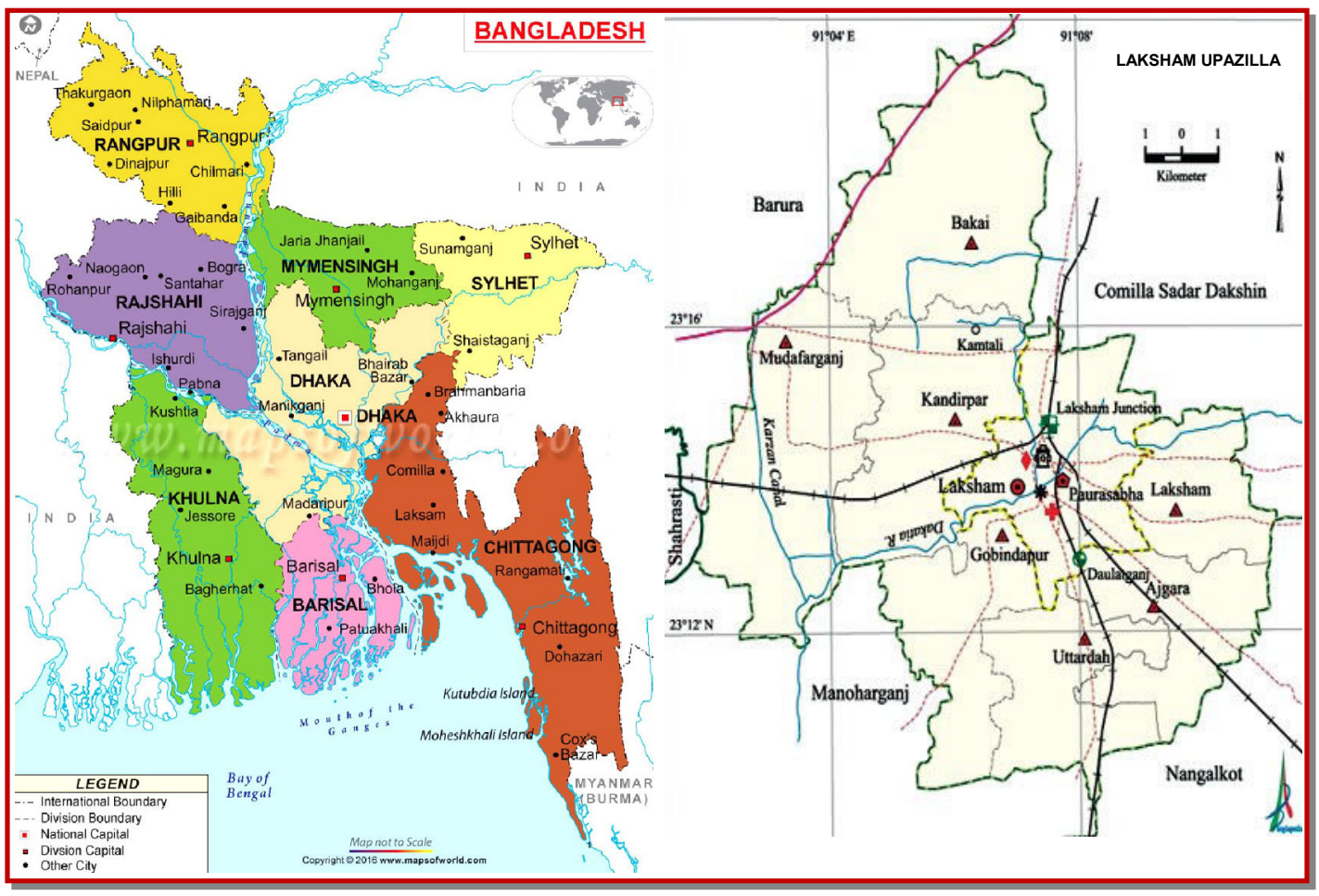

Figure 1: Map of Laksam Upazilla, Kandirpar Union 
Total population Patients

\begin{tabular}{|c|c|c|}
\hline \multirow[t]{2}{*}{294,719} & & Laksham Upazilla (2011 Bangladesh Census; 430 sq km area) \\
\hline & 376 & Total number of patients listed in the Laksham Upazilla Health Complex \\
\hline \multirow{10}{*}{5,247} & $\sqrt{3}$ & \\
\hline & 110 & Patients with moderate to severe palmar arsenical keratosis \\
\hline & $\sqrt{3}$ & \\
\hline & 60 & Patients in Iruain Village \\
\hline & $\sqrt{3}$ & \\
\hline & 42 & Patients were enrolled for the study \\
\hline & $\sqrt{2}$ & \\
\hline & 37 & Patients got baseline treatment \\
\hline & $\sqrt{3}$ & \\
\hline & 32 & $\begin{array}{l}\text { Patients completed the total treatment }[\text { Dead }=1 \text {; refuse to take medicine }=2 ; \text { Loss to follow- } \\
\text { up }=2 \text { ] }\end{array}$ \\
\hline
\end{tabular}

Figure 2: Steps of selection of arsenicosis patients

cipate in the study (Figure 2). Each patient attended the Iruain Community Clinic once every 2 weeks for counseling, clinical examination and receiving treatment. The duration of this study was 17 months (March 2016 to July 2017).

\section{Participants}

The participants were: a) arsenicosis patients $(n=37), b)$ arsenic exposed volunteers $(n=20)$ and $c)$ healthy volunteers $(n=20)$.

\section{Inclusion and exclusion criteria}

The enrolment of patients was based on the inclusion and exclusion criteria. Inclusion criteria were the: a) patient age, 18-60 years; b) both male and female; c) moderate to severe degree of arsenical keratosis present on the palm; d) drinking arsenic contaminated water (>50 $\mu \mathrm{g} / \mathrm{L})$ for more than 6 month; and e) patient voluntarily agreed to participate. Exclusion criteria were the: a) patient age less than 18 or over 60 years; b) pregnant or lactating mother; c) psoriasis and eczema; d) Bowen's disease; e) any kind of systemic disease, inflammatory disease and infectious condition that affect skin (diabetes mellitus, rheumatoid arthritis, systemic lupus erythematosus, hepatitis); f) hypersensitivity to any medicine; g) patient taking any antifungal medicine, folic acid or iron for the last three months; $h$ ) patient who received anti-oxidant vitamins/minerals within the last three months and i) patient who did not voluntarily agree to participate.

Arsenic exposed volunteer was the family member of the patient. The healthy volunteer was from the same arsenic endemic area and had no history of drinking arsenic contaminated water. They agreed to participate in this study.

\section{Procedure}

The detailed history of each patient was taken by interviewing. Clinical examinations were done mainly based on the moderate to severe palmar arsenical keratosis. All the data were recorded in the case report form (CRF). All the patients were informed to visit the Community Clinic once every 2 weeks. The first author involved in counseling the patient, physical examination, collection of samples and distribution of medicines. Drinking water and nail samples of each patient were collected before prescribing the medicines. The skin swab was taken to identify the fungi during each visit. Nodules in the palm were identified as spotted or diffuse. Each of spotted nodule was measured by the slide calipers both before and after completion of treatment. Photographs were taken both before and after completion of treatment.

\section{Preparation of culture media}

Sterilized petri dishes were used to grow the fungi. The petri dish was removed from its packaging and separated the two halves. The Sabouraud dextrose agar media was autoclaved, cooled and carefully poured into the bottom half of the petri dish, just enough to form a layer over the bottom of the dish. The top half of the petri dish was quickly replaced to prevent any airborne bacteria from contaminating the experiment. Set the petri dishes aside for $30 \mathrm{~min}$ to 2 hours, until the Sabouraud dextrose agar media become hardened.

Petri dishes were stored in a refrigerator to prevent the water inside the dishes from evaporating. It also allowed the surface of the media to harden slightly, which prevented any tearing or gouging when the fungal sample was transferred. The petri dishes were placed upside down for storing in the refrigerator. This 
helped to prevent any condensation on the lid from dropping down and disrupting the growing surface. The media-filled petri dishes would be kept in the refrigerator for a couple of months.

\section{Collection of specimens}

Drinking water: The drinking water, used by the patient, was collected once before inclusion into the study to confirm the diagnosis of arsenicosis. For this purpose, one polypropylene bottle (100 mL size) with screw closure was supplied to each patient at the beginning of the study. Two drops of nitric acid were added to each bottle that acted as a preservative. The patient was requested to collect the drinking water (completely filled up the bottle) used by him/her and submitted to the first author on the next visit. Each bottle was marked with an identification number.

Nail: One transparent mini ziplock plastic sample bag (size: $10 \times 18 \mathrm{~cm}$ ) was supplied to each patient to collect his/her nails. Each patient was advised not to cut his/ her finger and toenails for two weeks. They were also advised not to use any nail polish during this period. On the day of nail collection, both hands and feet were washed with clean water, dried using a clean towel in order to remove water and finally cut the nail with a pair of nail clippers. It was advised not to use a blade. All the nail samples (200-500 mg) were collected in the plastic bag. Each bag was labeled with an identification number.

Skin swab: Skin samples were collected from the skin of five different sites (palm, dorsum of the hand, right axilla, front and back of the chest) of each patient (Khalil et al., 2016). Palm, front and back of the chest are the common sites of developing the clinical signs and symptoms of arsenicosis whereas the dorsum of the hand and axilla were taken as control. The swab from the right axilla was taken from the participants in order to maintain uniformity. In case of palm surface, either left or right palm was used for taking the swab. In that case, the severity of the lesion was considered. In case of severe arsenical keratosis in the left palm in comparison to right one, the swab was taken from the left palm. In addition, the dorsum of the left was used instead of the dorsum of the right hand. It was ensured that the patient was not taken any antibiotic for the last one week. At first, the purpose and procedure of the sampling were explained to the patient and gained verbal consent. Hands of the first author were washed and dried thoroughly. Hand gloves were used to conduct this procedure. It was ensured that the privacy and dignity were maintained throughout. The selected sites were gently rubbed with $70 \%$ alcohol in order to prevent bacterial contamination. One swab (look like a long cotton bud) was removed from the sterile packaging. If the area to be swabbed was relatively dry (for example, axilla), the swab was moistened using sterile sodium chloride. This helped to ensure that any organisms present to adhere it. The swab was gently passed over the area, ensuring minimal discomfort for the patient. The top lid of the sterile petri dish containing Sabouraud dextrose agar media was lifted and a squiggly line was drawn lightly in the media with the end of the swab. The lid was placed closing firmly. The sample was labeled carefully. The procedure was clearly documented. The gloves were discarded and the hands were washed thoroughly. The waste was disposed safely in accordance with the local policy.

\section{Transportation and storage of samples}

The water, nail and petri dishes containing skin swab were transported to the Bangabandhu Sheikh Mujib Medical University on the same day. The water and nail samples were stored at the Department of Pharmacology until analysis. Petri dishes were transferred to the Department of Microbiology and Immunology for culture of fungi.

\section{Culture of fungi}

The specimen containing Sabouraud dextrose agar media was kept at room temperature for 4-7 days. Each petri dish was observed by naked eye every 24 hours to see any fungal growth. After the full growth of the fungi, the type of the fungus was detected under a compound microscope by a microbiologist using normal saline and lactophenol cotton blue (LPCB) (Levinson, 2008). The sample was labeled with the identification number, the site from which the sample was taken, the date and time of sampling.

\section{Distribution of medicines}

Medicine was purchased from a local pharmaceutical company. Each patient received a small plastic bag containing 14 tablets of the combination of iron (150 $\mathrm{mg}$ ) and folic acid ( $0.5 \mathrm{mg}$ ) (medicines for 2 weeks). The patient was advised to swallow single tablet daily, with sufficient amount of drinking water (about $150 \mathrm{~mL}$ ). Immediately after taking the medicine, he/she tick marked in the appropriate space printed on a separate sheet as an evidence of compliance.

\section{Estimation of total arsenic}

The total arsenic level in the water and nail was estimated by SDDC method using spectrophotometer (UV-VIS spectrophotometer-1201, Shimadzu, Japan) at $525 \mathrm{~nm}$. The details of the method had already been described earlier (Bhuiyan et al., 2016).

\section{Statistical analysis}

The results were expressed as mean \pm standard deviation (SD). McNemar's test and Fisher exact test were used to estimate the level of significance of the difference. The value of significant difference was considered at $\mathrm{p}<0.05$. 


\section{Results}

Table I shows the comparison of some characteristics among the three groups. The mean age of the arsenic exposed volunteers was less than that of the patient or healthy volunteer. That is, the accompanied family member who participated in this study was younger than the patient. The mean amount of arsenic in the drinking water and the duration of arsenic exposure were same in the patient and arsenic exposed volunteer. The participation of male was lower than the female in all the three groups. All the patients had previous history of taking anti-oxidants irregularly. Anti-oxidants were supplied by the non-government organizations. The mean duration of keratosis was $6.5 \pm 3.9$ years. Only two patients were the smoker but none was alcoholic.

There was no growth of fungi visible in the naked eye in the petri dish containing medium at room temperature after inoculation of swab for the first 72 hours. The visible growth of the fungi appeared on day 4 and continued to expand up to day 7 . Then there was no further growth of fungi.

Four types of fungi (Aspergillus, Dermatophytes, Mucor and Fusarium) were identified in the skin of all the three groups of participants. There was no variation in the type of fungi among the three groups. There were a number of unidentified fungi detected in the skin swab of some participants. The microscopic examination of the Aspergillus confirmed either Aspergillus niger or Aspergillus flavus.

The incidence of Aspergillus, and Dermatophytes spp. in the skin of healthy volunteers was low (0-4 out of 20 cases) (Table II). The incidence of Mucor spp. in the skin of healthy volunteers was 5-12 out of 20 cases. The chronic administration of arsenic did not influence the growth of fungi. There were increased numbers of arsenicosis patients with Aspergillus and Dermatophytes in the skin. The incidence of Mucor spp. was decreased in arsenicosis. The number of patients having Aspergillus spp. in the palm and dorsum of the hand were not different significantly. The patients with Dermatophytes spp. were increased in all the five areas. However, statistically significant changes were observed in dorsum of the hand. Palm of the hand of arsenicosis did not cause any significant change of Mucor spp.

Fusarium spp. were found in only a small number of participants (data not shown). There were no significant changes among the three groups and five different sites.

Table III shows the effects of iron and folic acid supplementation on the pattern of fungus in five different sites of the skin in arsenicosis patients. Supplementation reduced the number of patients with Aspergillus and Dermatophytes in five different areas. The significant change of Aspergillus spp. occurred in the axilla and Dermatophytes spp. in the palm of the hand. The significantly increased number of patients with Mucor spp. was observed in all the areas of the skin except the palm.

The mean $( \pm$ SD) score of palmar keratotic nodular size was $39.9 \pm 8.2$ and after 12 weeks supplementation of iron and folic acid, it was $29.9 \pm 6.9$ (Figure 3). These changes were statistically significant $(\mathrm{p}<0.0001)$.

\section{Discussion}

The present study shows that the healthy human skin of the palm, dorsum, axilla and chest (front and back) contain only four species of fungi: Aspergillus, Dermatophytes, Mucor and Fusarium. In addition, the incidence

Table I

\begin{tabular}{|c|c|c|c|}
\hline \multicolumn{4}{|c|}{ Table I } \\
\hline \multicolumn{4}{|c|}{ Characteristics of participants } \\
\hline Characteristics & $\begin{array}{l}\text { Arsenicosis } \\
\quad(\mathrm{n}=37)\end{array}$ & $\begin{array}{l}\text { Arsenic exposed volunteers } \\
\qquad(\mathrm{n}=20)\end{array}$ & $\begin{array}{l}\text { Healthy volunteers } \\
\qquad(\mathrm{n}=20)\end{array}$ \\
\hline Age (years) & $48.6 \pm 10.1$ & $25.1 \pm 6.6$ & $41.1 \pm 11.5$ \\
\hline \multicolumn{4}{|l|}{ Gender } \\
\hline Male & 11 & 8 & 5 \\
\hline Female & 26 & 12 & 15 \\
\hline Male/female ratio & $1: 2.4$ & $1: 1.5$ & $1: 3$ \\
\hline Number of smokers & 2 & 2 & 1 \\
\hline Number of alcoholic & 0 & 0 & 0 \\
\hline $\begin{array}{l}\text { Duration of arsenic expo- } \\
\text { sure (years) }\end{array}$ & $11.6 \pm 5.0$ & $12.8 \pm 3.1$ & - \\
\hline $\begin{array}{l}\text { Amount of arsenic in tube } \\
\text { well water }(\mu \mathrm{g} / \mathrm{L})\end{array}$ & $326.5 \pm 247.0$ & $326.5 \pm 247.0$ & - \\
\hline Duration of keratosis (years) & $6.5 \pm 3.9$ & - & - \\
\hline
\end{tabular}


Table II

\begin{tabular}{|c|c|c|c|c|c|c|c|c|c|}
\hline \multicolumn{10}{|c|}{ Number of individuals showed the pre } \\
\hline \multirow{2}{*}{ Area } & \multicolumn{3}{|c|}{$\begin{array}{c}\text { Number of individual with } \\
\text { Aspergillus spp. }\end{array}$} & \multicolumn{3}{|c|}{$\begin{array}{l}\text { Number of individual with } \\
\text { Dermatophytes spp. }\end{array}$} & \multicolumn{3}{|c|}{$\begin{array}{c}\text { Number of individual with Mucor } \\
\text { spp. }\end{array}$} \\
\hline & $\begin{array}{l}\text { Arseni- } \\
\text { cosis } \\
(\mathrm{n}=37)\end{array}$ & $\begin{array}{c}\text { Arsenic } \\
\text { expo- } \\
\text { sure } \\
(n=20)\end{array}$ & $\begin{array}{l}\text { Healthy } \\
\text { volun- } \\
\text { teers } \\
(n=20)\end{array}$ & $\begin{array}{l}\text { Arseni- } \\
\text { cosis } \\
(\mathrm{n}=37)\end{array}$ & $\begin{array}{l}\text { Arsenic } \\
\text { expo- } \\
\text { sure } \\
(\mathrm{n}=20)\end{array}$ & $\begin{array}{l}\text { Healthy } \\
\text { volun- } \\
\text { teers (n } \\
=20)\end{array}$ & $\begin{array}{l}\text { Arseni- } \\
\text { cosis } \\
(\mathrm{n}=37)\end{array}$ & $\begin{array}{c}\text { Arsenic } \\
\text { expo- } \\
\text { sure } \\
(\mathrm{n}=20)\end{array}$ & $\begin{array}{c}\text { Healthy } \\
\text { volunteers } \\
(\mathrm{n}=20)\end{array}$ \\
\hline Palm of the hand & 12 & & 1 & 8 & 2 & 1 & 13 & 11 & 7 \\
\hline $\begin{array}{l}\text { Dorsum of the } \\
\text { hand }\end{array}$ & 11 & & 4 & 10 & $\begin{aligned} 0 \\
.01\end{aligned}$ & 2 & 8 & 11 & 5 \\
\hline Axilla & 10 & 2 & 1 & 4 & 1 & 1 & 6 & 005 & 12 \\
\hline Front of the chest & 12 & $p=0.005$ & 0 & 5 & 0 & 2 & 9 & 002 & 11 \\
\hline Back of the chest & 11 & $p=0.04$ & 1 & 5 & 1 & 0 & 8 & 12 & 8 \\
\hline
\end{tabular}

Fisher exact test was done

of Aspergillus and Dermatophytes is low (0-4 out of 20 cases). The chronic exposure to arsenic does not alter the incidence of Aspergillus, Dermatophytes and Mucor species. However, the patient of arsenicosis shows increased incidence of Aspergillus and Dermatophytes species. On the other hand, the incidence of Mucor species was decreased. The supplementation of iron and folic acid to the patient for 12 weeks reduced the incidence of Aspergillus (only in axilla), Dermatophytes (only in palm) and increased the incidence of Mucor (all the sites except palm).

Identification of fungi in the skin is a difficult task. Lower type and incidence of fungi in the healthy human skin may be due to the following factors: a) the method of collection of the skin sample, b) the method of identification, c) the site of sample collection, d) the culture media used, and e) the $\mathrm{pH}$ of the skin.

In this study, skin swab was taken. The sample may also be collected by scraping or punch biopsy. There is a chance of getting more fungi when skin scrapping or punch biopsy is done.

The identification of fungi in human skin can be done by either traditional culture or DNA sequence-based. Culture-based studies have shown relatively lower types of fungi. For example, only 18 types of fungi are reported using the traditional culture. The sequencing effort represents more than 80 fungal types in the healthy human skin. The use of PCR for the detection of fungi is particularly challenging. Fungi have cell walls that impede the efficient lysis of organisms and liberation of DNA, which can lead to false-negative PCR results.

The fungi Malassezia, Rhodotorula, Debaromyces, Cryptococcus, and in some sites, Candida are reported as fungal skin commensals (Roth and James, 1988). The most fungal organism in the normal healthy human forearm skin belongs to the Malassezia species (Paulino et al., 2006). 


\begin{tabular}{|c|c|c|}
\hline \multicolumn{3}{|c|}{ Table III } \\
\hline \multicolumn{3}{|c|}{$\begin{array}{l}\text { Effects of iron and folic acid supplementation on } \\
\text { the pattern of skin fungi in arsenicosis }\end{array}$} \\
\hline Area & $\begin{array}{l}\text { Before treatment } \\
\quad(\mathrm{n}=32)\end{array}$ & $\begin{array}{l}\text { After treatment } \\
\qquad(\mathrm{n}=32)\end{array}$ \\
\hline \multicolumn{3}{|l|}{ Aspergillus } \\
\hline Palm of the hand & 11 & 6 \\
\hline $\begin{array}{l}\text { Dorsum of the } \\
\text { hand }\end{array}$ & 9 & 2 \\
\hline Axilla & 10 & $3^{a}$ \\
\hline Front of the chest & 11 & 4 \\
\hline Back of the chest & 11 & 4 \\
\hline \multicolumn{3}{|l|}{ Dermatophytes } \\
\hline Palm of the hand & 7 & $0 \mathrm{a}$ \\
\hline $\begin{array}{l}\text { Dorsum of the } \\
\text { hand }\end{array}$ & 9 & 4 \\
\hline Axilla & 4 & 2 \\
\hline Front of the chest & 1 & 1 \\
\hline Back of the chest & 3 & 3 \\
\hline \multicolumn{3}{|l|}{ Mucor } \\
\hline Palm of the hand & 12 & 18 \\
\hline $\begin{array}{l}\text { Dorsum of the } \\
\text { hand }\end{array}$ & 7 & $18^{a}$ \\
\hline Axilla & 6 & $17 \mathrm{a}$ \\
\hline Front of the chest & 8 & $18^{a}$ \\
\hline Back of the chest & 7 & $18^{\mathrm{a}}$ \\
\hline
\end{tabular}

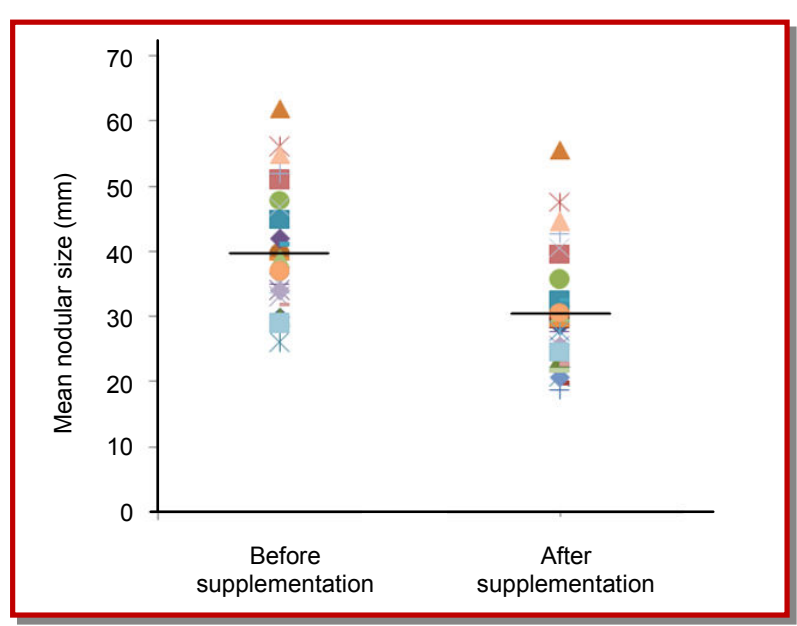

Figure 3: Mean nodular size ( $\mathrm{mm}$ ) before and after supplementation with iron and folic acid

Using the DNA sequencing technique, a single type of fungus, belonging to the genus Malassezia, is predominant on the head and trunk (Findley et al., 2013). Hands, which harbor a great diversity of bacteria, are the home for relatively few types of fungi. In contrast, feet, including toenails, heels and toe webs contain tremendous diversity. The most complex site is the heel which has about 80 types of fungi. On the other hand, about 60 types in toenail swab samples and 40 types in samples of the webs of the toes. Sites with moderate fungal diversity are inside the bend of the arm, inside of the forearm and palm, with each location supporting 18 to 32 genera of fungi. Head and trunk including the back, back of the neck, inside the ears, behind the ears, and between the eyebrows have fewer fungi types, with just 2 to 10 genera each.

In this study, Sabouraud dextrose agar media was used to culture the fungi. This media is used for general purpose. However, the media is nutritionally poor with acidic $\mathrm{pH}$ (5.6). Other media are corn meal agar, potato dextrose agar, V-8 juice agar, dung agar, Czapek-Dox medium, glucose-asparagine agar media, Neurosporacrassa minimal medium, inhibitory mould agar and Dermatophyte test media. Agar supplemented by rice, casein, and other nutrients like cornmeal agar with Tween 80 have been used to differentiate Candida species and Trichophytan species. Potato dextrose agar used to enhance conidia and pigment development of Trichophytan rubrum. Three parameters are important for the culture of fungi: a) nutrients (carbohydrate, nitrogen), $\mathrm{pH}$ (5 to 6$)$ and temperature $\left(15\right.$ to $\left.37^{\circ} \mathrm{C}\right)$.

The $\mathrm{pH}$ value of the skin influences the adherence of skin microflora (Lambers et al., 2006). An acid skin pH (4-4.5) keeps the resident bacterial flora attached to the skin, whereas an alkaline $\mathrm{pH}(8-9)$ promotes the dispersal from the skin. The $\mathrm{pH}$ of the normal skin is 47. It is not clear whether the skin $\mathrm{pH}$ of arsenicosis patient is changed from the normal individual.

Our skin cells live together with bacteria and fungi. The growth of bacteria and fungi in the skin is due to the presence of nutrients. These are secreted through the skin surface. Skin cells turn over every 4 weeks, differentiating from stem cells deep within the epidermis and hair follicles, and eventually slough off from the upper layer as cornified (enucleated, dead) cells (Blanpain et al. 2007).

The water loss from the body through skin occurs by sweating and transdermal water loss. Transdermal water loss is ten times more in the palm than the back of the skin (Baker and Kligman, 1967). Arsenic is also excreted through palm. There is more excretion of arsenic through the palm in patient of arsenicosis.

The secretion of arsenic from the skin was increased several fold in arsenic-exposed controls and patients in comparison to healthy volunteers. There was no difference in the skin lesions and unaffected sites of the patient. However, the secretion of cholesterol was significantly lower in the chest of patients and healthy controls. Secretions of vitamin E were low in healthy controls, higher in arsenic-exposed controls and highest 
in patients. Chronic intake of arsenic led to several folds higher secretion of zinc both in patients and in arsenicexposed controls. One molecule of arsenic appears to be co-secreted with two molecules of zinc (Yousuf et al., 2011). That is, chronic ingestion of arsenic changes the secretion of different compounds through the skin but these do not influence the fungal type and incidence.

Five different sites of the skin of arsenicosis patient show increased the incidence of Aspergillus and Dermato -phytes. There are no significant differences among the five sites in case of Aspergillus. The incidence of Dermatophytes in the palm and dorsum are increased in comparison to the other sites. On the other hand, the incidence of Mucor is decreased in all the sites except palm. Arsenic exposure can alter the skin bacterial pattern (Jyoti et al., 2011). The grown of Enterobacter spp. is more in the palm of arsenicosis patients than other sites of the skin (Khalil et al., 2016). Presence of Enterobactor species may influence the growth of Aspergillus and Dermatophytes species. For example, Pseudomonas aeruginosa was found to inhibit the growth of the corresponding Candida albicans strain in vitro (Kerr, 1994).

A cohort study conducted in Taiwan shows that fingernail infections are highly associated with arsenic exposure in a dose-dependent manner (Hsu et al., 2016). In this study, it is shown that chronic arsenic exposure does not influence the growth of fungi. Instead, the patient shows the increased incidence of the growth of fungi.

Aspergillus sp. P37 are tolerant to arsenic. Arsanate is taken by the cell through phosphate system (Canovas et al., 2004) where it reduces to arsenite and slowly pumped out of the cell.

In case of Dermatophytes, higher number of arsenicosis patients had these fungi in the palm and dorsum of the hand. Studies have shown that the hot and humid climate increase the fungal infection caused by Dermatophytes (Singh and Beena, 2003) and the cumulative arsenic exposure increase fungal growth (Hsu et al., 2016). However, there is no change found in the axilla, front and back of the chest.

The incidence of Mucor spp. in arsenicosis is increased which may be due to the presence of either Aspergillus or Dermatophytes.

After supplementation with iron and folic acid, significant changed occurred in two fungi Aspergillus and Dermatophytes in axilla and dorsum of hand respectively. Supplementation also reduces the size of keraticonodules.

\section{Ethical Issue}

The protocol was submitted to the Institutional Review Board of Bangabandhu Sheikh Mujib Medical University on June 26, 2016. The first author faced an interview with the IRB members on July 31, 2016. The protocol was revised according to the advices of the members. Finally it was approved (Registration No. BSMMU/2016/8308). This study was also registered in the www.clinicaltrials.gov (http:// bit.ly/2yws6tl) with Registration No. NCT02908581. The objective, nature, purpose and risk and benefit of all the procedures of this study were explained to each patient in easily understandable local language (Bangla). Each patient was also informed that he/she had the right to seek better treatment and also withdrawn him/herself from the study at any time. Written informed consent was also taken from each participant.

\section{References}

Baker H, Kligman AM. Measurement of transdermal water loss by electrical hygrometry: Instrumentation and responses to physical and chemical insults. Arch Dermatol. 1967; 96: pp $441-52$.

Bhuiyan HA, Tshering K, Misbahuddin M. Estimation of arsenic in nail using silver diethyldithiocarbamate method. Bangladesh J Pharmacol. 2015; 10: 513-17.

Blanpain C, Horsley V, Fuchs E. Epithelial stem cells: Turning over new leaves. Cell 2007; 128: 445-58.

Brinkel J, Khan MH, Kraemer A. A systematic review of arsenic exposure and its social and mental health effects with special reference to Bangladesh. Int J Environ Res Public Health. 2009; 6: 1609-19.

Canovas D, Vooijs R, Schat H, Lenz VD. The role of thiol species in the hypertolerance of Aspergillus spp. P37 to arsenic. J Biol Chem. 2004; 279: 51234-40.

Caussy D. A field guide for detection, management and surveillance of arsenicosis cases. World Health Organization, 2005, pp 6-7.

Chakraborti D, Rahman MM, Das B, Murrill M, Dey S, Mukherjee SC, Dhar RK, Biswas BK, Chowdhury UK, Roy S, Sorif S, Selim M, Rahman M, Quamruzzaman Q. Status of groundwater arsenic contamination in Bangladesh: A 14year study report. Water Res. 2010; 44: 5789-802.

Dina AN, Misbahuddin M. Randomized double-blind trial to evaluate the effectiveness of topical administration of propylene glycol in arsenical palmer keratosis. Bangladesh J Pharmacol. 2010; 5: 98-102.

Ferdous J, Misbahuddin M. Effect of ethanol extract of leaves of Azadirachta indica on palmar arsenical keratosis: A singleblind trial. Bangladesh J Pharmacol. 2014; 9: 279-83.

Findley K, Oh J, Yang J, Conlan S, Deming C, Meyer JA, Schoenfeld D, Nomicos E, Park M, NIH Intramural Sequencing Center Comparative Sequencing Program, Kong HH, Segre JA. Topographic diversity of fungal and bacte-rial communities in human skin. Nature 2013; 498: 367-70.

Guha Mazumder DN. Chronic arsenic toxicity: Clinical features, epidemiology, and treatment, experience in West Bengal. J Environ Sci Health Part A. 2003; 38: 141-63.

Hall AF. Arsenical keratosis disappearing with vitamin A 
therapy. Arch Derm Syph. 1946; 53: 154.

Hassan MM, Atkins PJ, Dunn CE. Social implications of arsenic poisoning in Bangladesh. Social Sci Med. 2005; 61: 220111.

Hsu LI, Cheng YW, Chen CJ, Wu MM, Hsu KH, Chiou $\mathrm{HY}$, Lee $\mathrm{CH}$. Cumulative arsenic exposure is associated with fungal infections: Two cohort studies based on southwestern and northeastern basins in Taiwan. Environ Int. 2016; 96: 173 -79 .

Islam AZMM, Misbahuddin M, Sikdar S, Biswas A K, Islam Z, Hadiuzzaman, Khandker S, Mahmud IA, Ahmad S A. Randomized controlled trial to evaluate the effectiveness of topical use of salicylic acid for treatment of keratosis in arsenicosis patients. In: Applied research on arsenic in Bangladesh. Misbahuddin M (ed.). Dhaka. World Health Organization (Bangladesh), Director General of Health Services, Govt. of Bangladesh, 2007, pp 92-100.

Jyoti A, Bonny TS, Hossain MA. Arsenic poisoning alters the composition of skin microbial flora of human. Res J Microbiol. 2011; 6: 524-33.

Kamaluddin M, Misbahuddin M. Zinc supplement on tissue arsenic concentration in rats. Bangladesh Med Res Counc Bull. 2006; 32: 87-91.

Kerr JR. Suppression of fungal growth exhibited by Pseudomonas aeruginosa. J Clin Microbiol. 1994; 32: 525-27.

Khalil N, Misbahuddin M, Sattar ANI. Pattern of skin bacteria in palmar arsenical keratosis. Bangladesh J Pharmacol. 2016; 11: $940-43$.

Lambers H, Piessens S, Bloem A, Pronk H, Finkel P. Natural skin surface $\mathrm{pH}$ is on average below 5 , which is beneficial for its resident flora. Int J Cosmet Sci. 2006; 28: 359-70.

Levinson W. Mycology. In: Review of medical microbiology and immunology. 10th ed. USA, The McGraw-Hill Company, 2008, pp 336-52.

Misbahuddin M, Afrin M. Effect of spirulina on the levels of zinc, vitamin $\mathrm{E}$ and linoleic acid in the palm skin extracts of people with prolonged exposure to arsenic. Bangladesh J Pharmacol. 2013; 8: 84-91.

Misbahuddin M, Bashar T, Hossain MA. Effectiveness of garlic oil in the treatment of palmar arsenical keratosis. Bangladesh J Pharmacol. 2013; 8: 22-27.

Misbahuddin M, Islam AZ, Khandker S, Ifthaker-Al-Mahmud, Islam N, Anjumanara. Efficacy of spirulina extract plus zinc in patients of chronic arsenicosis poisoning: A randomized placebo-controlled study. Clin Toxicol (Phila). 2006; 44: 13541.
Misbahuddin M, Momin A, Al-Amin M. All-E lutein and 3'epilutein concentrations in the epidermis of chronic arsenic poisoning. Clin Toxicol (Phil). 2008; 46: 176-80.

Misbahuddin M. Arsenicosis: A global issue. Science Publishing Group, New York, 2015, pp 1-204.

Nasir M, Misbahuddin M, Ali SMK. Selenium intervention in reducing arsenic levels in different tissues. In: Bangladesh Environment 2002, Proceedings of the 2nd International Conference on Bangladesh Environment. Ahmed MF, Tanveer SA, Badruzzaman ABM (eds). ICBEN-2002, Dhaka, Bangladesh, 2002, pp 343-52.

National micronutrient survey in Bangladesh, 2011-2012. https://www.spring-nutrition.org/sites/default /files/ events / files/presentation_anaemia_webinar_1.31.pdf

Paul PC, Misbahuddin M, Ahmed AN, Dewan ZF, Mannan MA. Accumulation of arsenic in tissues of iron-deficient rats. Toxicol Lett. 2002; 135: 193-97.

Paulino LC, Tseng CH, Strober BE, Blaser MJ. Molecular analysis of fungal microbiota in samples from healthy human skin and psoriatic lesions. J Clin Microbiol. 2006; 44: 2933-41.

Rahman M, Misbahuddin M. Effect of folic acid and tetrahydrofolate on tissue arsenic level in rat. Bangladesh J Pharmacol. 2010; 5: 25-29.

Rahman M, Tondel M, Ahmad SA, Axelson O. Diabetes mellitus associated with arsenic exposure in Bangladesh. Am J Epidemiol. 1998; 148: 198-203.

Rahman M, Tondel M, Ahmad SA, Chowdhury IA, Faruquee $\mathrm{MH}$, Axelson O. Hypertension and arsenic exposure in Bangladesh. Hypertension 1999; 33: 74-78.

Roth RR, James WD. Microbial ecology of the skin. Annu Rev Microbiol. 1988; 42: 441-64.

Saha KC. Melanokeratosis from arsenic contaminated tubewell water. Indian J Dermatol. 1984; 29: 37-46.

Sender R, Fuchs S, Milo R. Revised estimates for the number of human and bacteria cells in the body. PLoS Biol. 2016; 14: e1002533.

Singh S, Beena PM. Comparative study of different microscopic techniques and culture media of the isolation of dermatophytes. Indian J Med Microbiol. 2003; 21: 21-24.

Yousuf AKM, Misbahuddin M, Rahman MS. Secretion of arsenic, cholesterol, vitamin $\mathrm{E}$, and zinc from the site of arsenical melanosis and leucomelanosis in skin. Clin Toxicol. 2011; 49: 374-78.

Author Info

Mir Misbahuddin (Principal contact)

e-mail:mmisbah@bsmmu.edu.bd

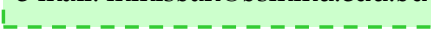

